\title{
Farklı kaide materyali kullanımının sınıf V restorasyonların mikrosızıntısı üzerine etkisi
}

\author{
İhsan Yıkılgan, Sinem Akgül," Aslı Kuşoğlu, \\ Oya Bala, Hüma Ömürlü, Emin Türköz \\ Diş Hastalıkları ve Tedavisi Anabilim Dalı, Gazi Üniversitesi \\ Diş Hekimliği Fakültesi, Ankara, Türkiye
}

\section{ÖZET}

AmAÇ: $\mathrm{Bu}$ çalışmanın amacı, sınıf $\mathrm{V}$ restorasyonların mikrosızıntısı üzerine farklı kaide materyallerinin kullanımının etkisini in vitro olarak incelemektir.

GeREÇ VE YönTEM: Çalışmada 60 adet çekilmiş, çürüksüz büyük azı dişi kullanıldı. Dişlerin bukkal yüzeyinde meziodistal geniş̧iği $4 \mathrm{~mm}$, okluzo-gingival genişliği $3 \mathrm{~mm}$ ve derinliği $3 \mathrm{~mm}$ olan sınıf $\mathrm{V}$ kaviteler hazırlandı. Daha sonra, dişler rastgele beş gruba ayrıldı: Grup 1: rezin modifiye kalsiyum silikat materyal (TheraCal LC), Grup 2: kendinden pürüzlendirmeli akışkan kompozit rezin (Fusio Liquid Dentin), Grup 3: akışkan kompozit rezin (Tetric N-Flow), Grup 4: nanodolduruculu rezin modifiye cam iyonomer siman (Ketac N100), Grup 5: kontrol grubu. Deney gruplarında, kaide materyalleri kavite tabanlarına $1 \mathrm{~mm}$ kalınlığında yerleştirildi. Üzerlerine A2 renginde nanohibrit dolduruculu kompozit rezin (Grandio) yerleştirilerek restorasyonlar tamamlandı. Kontrol grubunda ise herhangi bir kaide materyali kullanılmadı. Bitim ve polisaj işlemlerinden sonra, dişlere 5-55 ${ }^{\circ} \mathrm{C}$ 'de 5000 defa ısısal döngü uygulandı. Dișlerin mikrosızıntı değerlendirmeleri boya sızıntı yöntemi (\%0.5 bazik fuksin) kullanılarak gerçekleştirildi. Elde edilen skorlar, Bonferroni düzeltmeli Kruskal Wallis ve Mann-Whitney U testleri kullanılarak istatistiksel olarak incelendi.

BULGULAR: Çalışmadaki tüm deney gruplarında, restorasyonların okluzal bölgelerindeki mikrosızıntı skorları arasında istatistiksel olarak anlamlı fark bulunmazken ( $p=0.267)$, gingival bölgedeki mikrosızıntı skorları arasında istatistiksel olarak anlamlı farklılık olduğu görüldü $(p=0.004)$. Buna göre, Fusio Liquid Dentin ve kontrol gruplarına göre sırasıyla, Theracal LC, Tetric $\mathrm{N}$-Flow ve Ketac $\mathrm{N}-100$ gruplarının sızdırmazlıklarının anlamlı olarak daha iyi olduğu görüldü $(p<0.01)$. Tüm deney gruplarında okluzal ve gingival bölgelerde gözlenen mikrosızıntı skorları arasında istatistiksel olarak anlamlı farklıı̆ıın olmadığı tespit edildi ( $p>0.01)$.

Makale gönderiliş tarihi: 27 Ocak 2016; Yayına kabul tarihi: 6 Ekim 2016 * Iletişim: Dr. Sinem Akgül, Gazi Üniversitesi, Diş Hekimliği Fakültesi, Diş Hastalıkları ve Tedavisi Anabilim Dalı, 8. Cadde, 06510, Emek, Ankara, Türkiye; E-posta: sinemakipek@gmail.com
Sonuç: Bu çalıșmanın sınırları dahilinde sınıf V restorasyonlarda kaide materyali kullanımının (Fusio Liquid Dentin hariç) gingival bölgedeki mikrosızıntıyı azalttığı görüldü.

Anahtar Kelimeler: Dental kavite kaplayıcıları; dental sızıntı; kompozit dental rezin

Kaynak Göstermek İçin: Yıkılgan İ, Akgül S, Kuşoğlu A, Bala $\mathrm{O}$, Ömürlü $\mathrm{H}$, Türköz $\mathrm{E}$. Farklı kaide materyali kullanımının sınıf $\mathrm{V}$ restorasyonların mikrosızıntısı üzerine etkisi. Acta Odontol Turc 2017;34(1):31-7

EDiтöR: Güven Kayaoğlu, Gazi Üniversitesi, Ankara, Türkiye

YAYIN HAKKI: (C) 2017 Yıkılgan ve ark. Bu eserin yayın hakkı Creative Commons Attribution License ile ruhsatlandırılmıştır. Sınırsız kullanım, dağıtım ve her türlü ortamda çoğaltım, yazarlar ve kaynağın belirtilmesi kaydıyla serbesttir.

[Abstract in English is at the end of the manuscript]

\section{Giriş}

Diş sert doku lezyonlarının sıklıkla gözlendiği yerlerden biri dişlerin servikal bölgelerdir. ${ }^{1}$ Servikal bölgede oluşan lezyonlar, çürük nedeniyle oluşabileceği gibi çürüksüz olarak da meydana gelebilir. Başlangıç halindeki küçük boyutlardaki servikal lezyonlarda hassasiyet mevcut değilse, beslenme alışkanlığı ve oral hijyen eğitimi ile lezyonlar kontrol altında tutulabilir. Ancak, hassasiyet veya ağrı varsa, lezyon derinse ve en önemlisi çürük içeriyorsa bu tip lezyonlar mutlaka restore edilmelidir. ${ }^{1}$

Servikal bölge restorasyonlarının klinik başarılarını etkileyen en önemli etkenlerden biri kenar sızıntısıdır. Kenar sızıntısı; restorasyon ile diş dokuları arasından bakteri, sıvı, molekül ve iyonların mikroskobik olarak geçişi şeklinde tanımlanmaktadır. ${ }^{2}$ Mikrosızıntı sonucu; post-operatif hassasiyet, kenar renklenmesi, kenar bütünlüğünün bozulması ve sekonder çürük gibi birçok olumsuz durumla karşı karşıya kalınabilir. ${ }^{3}$ Servikal bölge restorasyonlarında mikrosızıntı oluşmasında etkili iki temel neden vardır. Bunlar; lezyonların dişetine yakınlığı sebebiyle uygulama esnasında nem kontrolünün zor olması ve fonksiyonel kuvvetlerin dişin servikal bölgesinde stres oluşturmasıdır.

Dişlerde oluşan çeşitli streslerin olumsuz etkilerini azaltmak amacıyla, kompozit rezin ile kavite duvarları arasına düşük elastisiteye sahip stres kırıcı kaide 
materyallerinin kullanımı tavsiye edilmektedir. ${ }^{4}$ Kaide materyalinin kullanımıyla, hem okluzal kuvvetlere bağlı oluşan streslerin hem de polimerizasyon büzülmesi sonucu kompozit rezinin yapısında oluşan streslerin kontrolü amaçlanır. Rezin modifiye cam iyonomer simanlar ve akışkan kompozit rezinler, kompozit rezin ile yapılan restorasyonlarda kullanılabilen kaide materyalleridir. Son yıllarda geliştirilen kendinden bağlayıcılı akışkan kompozit rezinler de alternatif kaide materyalleri arasında gösterilmektedir. Asitle pürüzlendirme ve bağlayıcı uygulamasının gerekmediği bu materyaller, uygulama kolaylığının yanı sıra hassasiyet giderici özelliğe de sahiptirler.

Restoratif diş hekimliğinde kaide kullanımının diğer bir amacı da pulpanın korunması amacıyla direkt ya da indirekt olarak pulpa yüzeyinin kapatılmasıdır. Bu amaçla geliştirilmiş materyaller arasında en sık tercih edileni kalsiyum hidroksit esaslı kaide materyalleridir. ${ }^{5}$ Bunların avantajlarının yanında kolay çözünebilmeleri ve materyal ile pulpa ara yüzeyinde $\mathrm{pH}^{\prime} \mathrm{yi}$ arttırarak nekrotik yüzey oluşturmaları gibi ciddi dezavantajları da vardır. ${ }^{5}$ 1990'larda üretilen mineral trioksit agregat (MTA), kalsiyum hidroksit esaslı materyallere kıyasla üstün özellikler gösteren bir alternatif olmuştur. MTA; biyoaktif, biyouyumlu, diş pulpasıyla olumlu etkileşimi ve daha az pulpa inflamasyonuna sebep olması gibi nedenlerle günümüzde pulpa kaplamasında başarıyla kullanılmaktadır. ${ }^{5}$ MTA'nın pulpa kaplaması tedavisindeki başarısından yola çıkılarak, ışıkla sertleşen rezin modifiye kalsiyum silikat materyal, TheraCal LC (Bisco Inc, Schaumburg, IL, ABD) üretilmiştir. Üretici firma, TheraCal LC'nin hidrofilik monomer içinde trikalsiyum silikat partiküllerini içeren bir materyal olduğunu, pulpa yüzeyindeki pH'yi arttırarak ( $\mathrm{pH}$ 10-11) pulpada rejeneratif olayların başlamasında, kalsiyum salımı ile hidroksi apatit oluşumunda ve sekonder dentin köprülerinin oluşmasında önemli rol oynadığını bildirmiştir. Ayrıca materyalin opak olması nedeniyle özellikle kompozit materyal ile kullanılacaksa 1 mm'den fazla kalınlıkta kullanılmaması gerektiğini de belirtmişlerdir. Ancak literatürde bu materyalin diş dokusuna bağlanımı ve dolayısıyla mikrosızıntı üzerine etkisiyle ilgili yeterli bilgi bulunmamaktadır.

$\mathrm{Bu}$ çalışmanın amacı, sınıf $\mathrm{V}$ restorasyonların mikrosızıntısı üzerine farklı kaide materyali kullanımın etkisini in vitro olarak incelemektir. Çalışmanın başlangıç hipotezi, sınıf $\bigvee$ restorasyonlarda mikrosızıntı oluşumunu önlemede kaide materyali kullanımı ile kullanılmaması arasında anlamlı bir farklılığın olmadığıdır.

\section{Gereç Ve Yöntem}

Çalışmada periodontal sebeplerle çekilmiş 60 adet çürüksüz birinci büyük azı dişi kullanıldı. Dişlerin yüzeylerindeki yumuşak doku artıkları keskin bir ekskavatör ile temizlendikten sonra, diş ve kök yüzeylerinde çatlak ve kırık olup olmadığı stereomikroskop (Olympus SZ60, Tokyo, Japonya) ile incelendi. Çatlak ve kırık saptanan dişler çalışmaya dahil edilmedi. Bu incelemeden sonra dişler çalışmada kullanılıncaya kadar \%0.9 serum fizyolojik içinde bekletildi.

\section{Restorasyonların hazırlanması}

Dişlerin bukkal yüzüne fissür uçlu elmas frez (Diatech, Swiss Dental, Heerbrugg, İsviçre) ile, kavitenin gingival sınırı mine-sement birleşiminin $1 \mathrm{~mm}$ altında olacak şekilde, boyutları: $4 \mathrm{~mm}$ (mezio-distal) $\times 3 \mathrm{~mm}$ (gingivo-okluzal) $\times 3 \mathrm{~mm}$ (derinlik) sınıf $\mathrm{V}$ kaviteler hazırlandı. Kavite preparasyonları esnasında milimetrik uçlu periodontal sond kullanılarak kavite boyutlarında sapma olmamasına dikkat edildi. Kavite preparasyonu tamamlanan dişler, her grupta 12 diş olacak şekilde rastgele beş gruba ayrıldı.

Grup 1: rezin modifiye kalsiyum silikat materyal, TheraCal LC,

Grup 2: kendinden bağlanabilen akışkan kompozit rezin, Fusio Liquid Dentin (Pentron Clinical, Orange, CA, ABD),

Grup 3: nanohibrit dolduruculu akışkan kompozit rezin, Tetric N-Flow (Ivoclar-Vivadent, Schaan, Liechtenstein),

Grup 4: nanodolduruculu rezin modifiye cam iyonomer siman, Ketac N100 (3M-ESPE, St. Paul, MN, ABD) kavite tabanına kaide materyali olarak $1 \mathrm{~mm}$ kalınlığında yerleştirildi. Materyaller Tablo 1'de açıklandığı şekilde üretici firmalarının talimatları doğrultusunda kullanıldı. Materyallerin polimerizasyonunda LED ışık cihazı (Free Light Elipar, 3M-ESPE, St. Paul, MN, ABD) kullanıldı.

Tetric N-Flow'un kullanıldığı Grup 3 haricinde, kaide materyali yerleştirildikten sonra tüm kavite yüzeylerine tek aşamalı kendinden pürüzlendirmeli adeziv sistem (Clearfil S3 Bond, Kuraray, Noritake Dental, Tokyo, Japonya) üretici firma talimatları doğrultusunda uygulandı ve $10 \mathrm{sn}$ ışık uygulanarak polimerize edildi. Grup 3'te ise önce kaviteye adeziv uygulandı ve daha sonra Tetric N-Flow kaviteye yerleştirildi.

Takiben, A2 renginde nanohibrit dolduruculu bir kompozit rezin olan Grandio (VOCO GmbH, Cuxhaven, Almanya),kaide materyalinin üzerine $2 \mathrm{~mm}$ kalınlığında yerleştirilip LED ışık cihazı ile 20 sn ışık uygulanarak polimerize edildi.

Grup 5'teki dişlerin kavite tabanlarına ise kaide materyali kullanılmadan kompozit restorasyonları diğer deney gruplarında uygulandığı şekilde adeziv uygulamasından sonra yapılarak, kontrol grubu oluşturuldu.

Restore edilen tüm deney gruplarındaki dişlere, alüminyum oksit kaplı diskler (Sof-Lex, 3M ESPE, St. Paul, MN, ABD) kullanarak bitirme ve polisaj işlemleri uygulandıktan sonra, hazırlanan dişler $37^{\circ} \mathrm{C}$ nemli enkübatörde 24 saat süreyle saklandı. Bu sürenin sonunda, tüm dişlere 5-55 ${ }^{\circ} \mathrm{C}$ 'de ve her birinde $15 \mathrm{sn}$ kalacak şekilde 5000 kere ısısal döngü uygulandı. Takiben, restorasyon kenarları $1 \mathrm{~mm}$ açıkta kalacak şekilde tüm diş yüzeyi iki kat tırnak cilasıyla boyandı. 
Tablo 1. Çalışmada kullanılan materyallerin tipi ve içerikleri

\begin{tabular}{|c|c|c|c|}
\hline Materyaller & Tipi & İçerik & Uygulanışı \\
\hline $\begin{array}{l}\text { TheraCal LC } \\
\text { (Bisco Inc, } \\
\text { Schaumburg, IL, } \\
\text { ABD) }\end{array}$ & $\begin{array}{l}\text { Rezin modifiye } \\
\text { kalsiyum silikat } \\
\text { materyal }\end{array}$ & $\begin{array}{l}\text { Tip III portlan siman, radyoopak materyal, } \\
\text { hidrofilik silika, rezin (hidrofobik monomer; } \\
\text { TriEDMA, TEGDMA, UDMA, Bis-GMA, } \\
\text { hidrofilik monomer; HEMA, PEGDMA) }\end{array}$ & $\begin{array}{l}\text { Kavite tabanına } 1 \mathrm{~mm} \text { kalınlığında yerleştirildi. } 20 \mathrm{sn} \text { ışık } \\
\text { uygulanarak polimerize edildi. }\end{array}$ \\
\hline $\begin{array}{l}\text { Fusio Liquid Dentin } \\
\text { (Pentron Clinical, } \\
\text { Orange, CA, ABD) }\end{array}$ & $\begin{array}{l}\text { Kendinden adezivli } \\
\text { akışkan kompozit }\end{array}$ & $\begin{array}{l}\text { UDMA, TEGDMA, HEMA, 4-MET, } \\
\text { nano boyutta amorf silika silanlanmış } \\
\text { baryumborosilikat cam }\end{array}$ & $\begin{array}{l}\text { Kavite tabanına } 1 \mathrm{~mm} \text { kalınlığında yerleştirildi ve şırınga } \\
\text { ucuyla hafifçe kavite yüzeyine yayıldı. } 10 \mathrm{sn} \text { ışık uygulanarak } \\
\text { polimerize edildi. }\end{array}$ \\
\hline $\begin{array}{l}\text { Tetric N Flow } \\
\text { (Ivoclar - Vivadent, } \\
\text { Schaan, } \\
\text { Liechtenstein) }\end{array}$ & $\begin{array}{l}\text { Nanohibrit akışkan } \\
\text { kompozit rezin }\end{array}$ & $\begin{array}{l}\text { TEGDMA, doldurucu (baryum cam, } \\
\text { yitterbium triflorid, silika), reaksiyon } \\
\text { başlatıcı, stabilize edici ve pigmentler }\end{array}$ & $\begin{array}{l}\text { Tüm kavite yüzeyine Clearfil S3 Bond uygulandı ve } 10 \mathrm{sn} \\
\text { ışık uygulanarak polimerize edildi. Takiben Tetric N-Flow } \\
1 \mathrm{~mm} \text { kalınlığında kavite tabanına uygulandı ve } 20 \mathrm{sn} \text { ışık } \\
\text { uygulanarak polimerize edildi. }\end{array}$ \\
\hline $\begin{array}{l}\text { Ketac N100 } \\
\text { (3M-ESPE, St. Paul, } \\
\text { MN, ABD) }\end{array}$ & $\begin{array}{l}\text { Nano dolduruculu } \\
\text { rezin modifiye cam } \\
\text { iyonomer siman }\end{array}$ & $\begin{array}{l}\text { Deionize su, HEMA, FAS, nanomerler } \\
\text { ve nanobağlayıcılar, metakrilat modifiye } \\
\text { polialkenoik asit }\end{array}$ & $\begin{array}{l}\text { Hafif kurutulan kavite yüzeyine Ketac N100'ün primer'i } \\
\text { uygulandı. Takiben } 10 \mathrm{sn} \text { hava ile kurutuldu ve } 10 \mathrm{sn} \text { ışık } \\
\text { uygulanarak polimerize edildi. Üzerine } 1 \mathrm{~mm} \text { kalınlığında Ketac } \\
\text { N100 yerleştirildi ve } 20 \mathrm{sn} \text { ışık uygulanarak polimerize edildi. }\end{array}$ \\
\hline $\begin{array}{l}\text { Grandio } \\
\text { (VOCO GmbH, } \\
\text { Cuxhaven, Almanya) }\end{array}$ & $\begin{array}{l}\text { Nanohibrit } \\
\text { dolduruculu } \\
\text { kompozit rezin }\end{array}$ & $\begin{array}{l}\text { BISGMA, TEGDMA, } 1.5 \mu \text { m büyüklükte } \\
\text { cam doldurucu, } 20 \text { nm büyüklükte } \\
\text { nanodoldurucular }\end{array}$ & $\begin{array}{l}2 \mathrm{~mm} \text { kalınlıkta olacak şekilde kaviteye yerleştirildi ve } 20 \text { sn } \\
\text { Işık uygulanarak polimerize edildi. }\end{array}$ \\
\hline
\end{tabular}

Cila kuruduktan sonra dişler $\% 0.5$ bazik fuksin içinde 24 saat bekletildi. Boyadan çıkarılan dişler akan su altında yıkandı. Dişler restorasyonun ortasından geçecek şekilde bukko-lingual yönde enlemesine iki eşit parçaya ayrıldı. Her parçada restorasyon kenarlarında oluşan boya sızıntısı aynı araştırmacı tarafından stereomikroskop (Olympus SZ60, Tokyo, Japonya) ile $\times 40$ büyütmede incelendi ve diş ile restorasyon ara yüzeyinde kavite duvarlarında oluşan boya sızıntısı aşağıda belirtilen şekilde skorlandı. ${ }^{6}$

Skor 0: Hiç boya sızıntısı yok

Skor 1: 0-1 $\mathrm{mm}$ boya sızıntısı mevcut

Skor 2: 1-2 $\mathrm{mm}$ boya sızıntısı mevcut

Skor 3: 2 mm'den fazla boya sızıntısı mevcut

\section{İstatistiksel analiz}

Verilerin analizi SPSS for Windows 11.5 paket programında yapıldı (Statistical Package for Social Science; SPSS Inc., Chicago, IL, ABD).

Gruplar arasında okluzal veya gingival boya sızıntı skorları yönünden farkın önemliliği Bonferroni düzeltmeli Kruskal Wallis testiyle araştırıldı. Bonferroni Düzeltmesine göre $p<0.025$ için sonuçlar istatistiksel olarak anlamlı kabul edildi. Kruskal Wallis test istatistiği sonucunun önemli bulunması halinde farka neden olan grupları tespit etmek amacıyla Conover'in parametrik olmayan çoklu karşılaştırma testi kullanıldı ( $p<0.025)$.

Gruplar içerisinde okluzal ve gingival boya sızıntı skorları arasında istatistiksel olarak anlamlı fark olup olmadığı ise Bonferroni Düzeltmeli Mann-Whitney $U$ testiyle araştırıldı. Bonferroni düzeltmesine göre $p<0.010$ için sonuçlar istatistiksel olarak anlamlı kabul edildi.

$\mathrm{Bu}$ çalışmada, olası tüm çoklu karşılaştırmalarda Tip I hatayı kontrol edebilmek için Bonferroni düzeltmesi yapıldı.

\section{BULGULAR}

Theracal LC, Fusio Liquid Dentin, Tetric N-Flow, Ketac $\mathrm{N}-100$ ve kontrol grupları arasında okluzal bölgede sızdırmazlık bakımından istatistiksel olarak anlamlı fark görülmedi ( $p=0.267$, Kruskall-Wallis; Tablo 2).

Theracal LC, Fusio Liquid Dentin, Tetric N Flow, Ketac N-100 ve kontrol gruplarından en az ikisi arasında gingival bölgede sızdırmazlık bakımından istatistiksel olarak anlamlı fark görüldü ( $p=0.004$, Kruskall-Wallis). Söz konusu farka neden olan durum istatistiksel olarak değerlendirildiğinde, Liquid Dentin ve kontrol gruplarına göre sırasıyla; Theracal LC, Tetric N Flow ve Ketac $\mathrm{N}-100$ gruplarının sızdırmazlıklarının anlamlı olarak daha iyi olduğu görüldü $(p<0.01)$.

Grupların okluzal ve gingival bölgedeki sızdırmazlık skorları kendi içerisinde değerlendirildiğinde, hiç bir grupta okluzal ve gingival bölge arasında istatistiksel olarak anlamlı fark olmadığı belirlendi ( $p>0.01$; Tablo 2, Şekil 1).

\section{TARTIŞMA}

Günümüzde insanların estetik taleplerinin artması, restoratif amaçla kullanılan materyallerin gelişiminde önemli rol oynamıştır. Bu gelişmeler sayesinde materyallerin estetik görünümü, okluzal kuvvetlere karşı dayanımı ve aşınma direnci gibi problemler oldukça azalmıştır. Tüm bu olumlu gelişmelere rağmen, restorasyon kenarlarında mikrosızıntı oluşumu hala oldukça önemli bir problemdir. ${ }^{7}$ Mikrosızıntının, mevcut restorasyonlarda estetik kayıp ve hatta pulpada patalojik durumların ortaya çıkmasının en önemli nedenlerinden biri olduğu birçok literatürde yayınlanmıştır., ${ }^{7,8}$

Mikrosızıntı; tüm restorasyon tiplerinde önemli bir problem olmakla beraber, özellikle dişin servikal bölgesinde yer alan restorasyonlarda daha büyük önem taşımaktadır. Çünkü bu tip restorasyonların dişteki lokalizasyonu sadece minede değil dentin ve sement 
Tablo 2. Çalışmada incelenen deney ve kontrol gruplarından elde edilen skorların istatistiksel değerlendirme sonuçları

\begin{tabular}{|c|c|c|c|c|c|c|c|}
\hline & $\begin{array}{c}\text { Grup } 1 \\
\text { (TheraCal LC) }\end{array}$ & $\begin{array}{c}\text { Grup } 2 \\
\text { (Fusio Liquid Dentin) }\end{array}$ & $\begin{array}{c}\text { Grup } 3 \\
\text { (Tetric N-Flow) }\end{array}$ & $\begin{array}{c}\text { Grup } 4 \\
\text { (Ketac N-100) }\end{array}$ & $\begin{array}{c}\text { Grup 5 } \\
\text { (Kontrol) }\end{array}$ & Toplam & $\begin{array}{c}\text { p-değeri } \\
\text { (Gruplar-arası } \\
\text { karşılaştırma) }\end{array}$ \\
\hline Okluzal & & & & & & & 0.267 \\
\hline Skor 0 & $8(\% 66.7)$ & $2(\% 16.7)$ & $6(\% 50.0)$ & $4(\% 33.3)$ & $4(\% 33.3)$ & 24 (\%40.0) & \\
\hline Skor 1 & $4(\% 33.3)$ & $6(\% 50.0)$ & $6(\% 50.0)$ & $6(\% 50.0)$ & 4 (\%33.3) & 26 (\%43.3) & \\
\hline Skor 2 & - & $2(\% 16.7)$ & - & $2(\% 16.7)$ & $2(\% 16.7)$ & $6(\% 10.0)$ & \\
\hline Skor 3 & - & $2(\% 16.7)$ & - & - & $2(\% 16.7)$ & $4(\% 6.7)$ & \\
\hline Toplam & $12(\% 100.0)$ & $12(\% 100.0)$ & $12(\% 100.0)$ & $12(\% 100.0)$ & $12(\% 100.0)$ & $60(\% 100.0)$ & \\
\hline Gingival & & & & & & & 0.004 \\
\hline Skor 0 & $6(\% 50.0)$ & - & $6(\% 50.0)$ & $4(\% 33.3)$ & $2(\% 16.7)$ & $18(\% 30.0)$ & \\
\hline Skor 1 & $6(\% 50.0)$ & $2(\% 16.7)$ & 4 (\%33.3) & $6(\% 50.0)$ & - & $18(\% 30.0)$ & \\
\hline Skor 2 & - & - & $2(\% 16.7)$ & $2(\% 16.7)$ & $4(\% 33.3)$ & $8(\% 13.3)$ & \\
\hline Skor 3 & - & $10(\% 83.3)$ & - & - & $6(\% 50.0)$ & $16(\% 26.7)$ & \\
\hline Toplam & $12(\% 100.0)$ & $12(\% 100.0)$ & $12(\% 100.0)$ & $12(\% 100.0)$ & $12(\% 100.0)$ & $60(\% 100.0)$ & \\
\hline $\begin{array}{c}\text { p-değeri } \\
\text { (Grup-içi } \\
\text { karșılaștırma) }\end{array}$ & 0.699 & 0.065 & 0.818 & 1.000 & 0.180 & - & - \\
\hline
\end{tabular}

Gruplar-arası post hoc istatistiksel analizde gingival taraf için Grup 1-Grup 2, Grup 1-Grup 5, Grup 2-Grup 3, Grup 2-Grup 4, Grup 3-Grup 5 arasında (p<0.001), ve Grup 4-Grup 5 arasında ( $p=0.004)$ istatistiksel olarak anlamlı fark bulundu.

dokusunu da içermektedir. Rezin esaslı kompozit materyallerinyapısında polimerizasyon sonucu birmiktar büzülmenin oluşması, farklı dokulara bağlanmanın gerçekleştiği servikal restorasyonların kavite duvarlarına adaptasyonunu bozduğu ve dolayısıyla mikrosızıntıya neden olduğu rapor edilmiştir. ${ }^{9}$

Restorasyon kenarlarında oluşan mikrosızıntı; boyama yöntemi, radyoizotop yöntemi, kimyasal ajanlar, elektrokimyasal analiz, bakteriyel sızıntı, insan serumu sızıntısı yöntemi, basınçlı hava kullanımı, taramalı elektron mikroskopu (SEM) analizi ve nötron aktivasyon analizi gibi birçok değişik yöntemle tespit edilebilmektedir. ${ }^{10} \mathrm{Bu}$ yöntemler arasından boya sızıntısı yöntemi; kimyasal reaksiyona ve radyasyona intiyaç duyulmaması, ucuz ve kolay uygulanabilir olmalarından dolayı sıklıkla tercih edilmektedir. ${ }^{11}$

Çalışmada tüm deney gruplarının okluzal bölgelerinden elde edilen mikrosızıntı skorları değerlendirildiğinde, gruplar arasında istatistiksel olarak anlamlı bir farklılık olmadığı gözlendi. Senawongse ve ark. ${ }^{12}$ tarafından yapılan bir çalışmada, sınıf V restorasyonların mikrosızıntısı üzerine kaide materyali kullanımının etkisi değerlendirilmiş, kaide materyali kullanımının restorasyonların gingival bölgesinde görülen mikrosızıntı oluşumunu azaltırken, okluzal bölgede görülen mikrosızıntı üzerine herhangi bir etkisinin olmadığı bildirilmiştir. Bu çalışma bizim çalışmamızın bulgularını desteklemektedir. Bu durum kompozit materyalin kavite duvarlarına bağlanmasında okluzal bölgede daha fazla mine, gingival bölgede ise dentinin olmasından ileri gelebilir. Restorasyonların mikrosızıntı üzerine yapılan birçok çalışmada minede sonlanan restorasyon kenarlarında mikrosızıntının dentin veya sementte sonlanan restorasyonlara göre daha az olduğu bildirilmiştir. ${ }^{13-15}$
Çalışmada elde edilen gingival bölgedekimikrosızıntı skorları değerlendirildiğinde; kaide materyali olarak rezin modifiye kalsiyum silikat materyal, TheraCal LC'nin kullanıldığı Grup 1, nanohibrit dolduruculu akışkan kompozit rezin, Tetric N-Flow'un kullanıldığı Grup 3 ve nanodolduruculu rezin modifiye cam iyonomer siman, Ketac N100'ün kullanıldığı Grup 4'teki örneklerde gözlenen mikrosızıntının hiç kaide materyali kullanılmayan kontrol grubu (Grup 5) ve kendinden bağlanabilen akışkan kompozit rezin, Fusio Liquid Dentin'in kullanıldığı Grup 2'deki örneklerde gözlenen mikrosızıntıdan istatistiksel olarak anlamlı bir şekilde daha az olduğu tespit edildi. Bunun kullandığımız kaide materyallerinin yapısal özelliklerinin ve uygulamalarının birbirinden farklı olması neden olabilir.

Kaide materyallerinin düşük elastisiyet modüllerinin, kompozit rezinin polimerizasyon büzülmesini kompanse etmenin yanı sıra kavitenin $C$ faktörü değerini düşürerek kompozit rezinin sızdırmazlığı üzerine katkıda bulunduğu rapor edilmiştir. ${ }^{15}$ Kaide materyali kullanımının bir diğer avantajı ise fonksiyon esnasında okluzal kuvvetlere bağlı oluşan gerilme ve makaslama kuvvetlerini tolere etmeleridir. ${ }^{16,17}$

$\mathrm{Bu}$ olumlu özelliklerinden dolayı günümüzde kompozit rezin ile birlikte kalsiyum hidroksit, cam iyonomer siman, MTA, akışkan kompozit gibi değişik kaide materyalleri kullanılmaktadır. Yakın zamanda ise kalsiyum hidroksit ve MTA'nın dentin yapımını teşvik edici özelliğini taşıyan yeni bir materyal geliştirilmiştir. TheraCal LC isimli bu materyal, tiksotropik özelliği nedeniyle uygulaması kolay bir materyaldir. Ayrıca hidrofilik rezin içeriği sayesinde stabil bir yapıya sahiptir. Estrela ve Holland ${ }^{18}$ ve Gondolfi ve ark. ${ }^{19}$ TheraCal LC'nin kullanma kolaylığından dolayı MTA'ya göre daha üstün tıkama özelliğine sahip olduğunu bildirmişlerdir. 


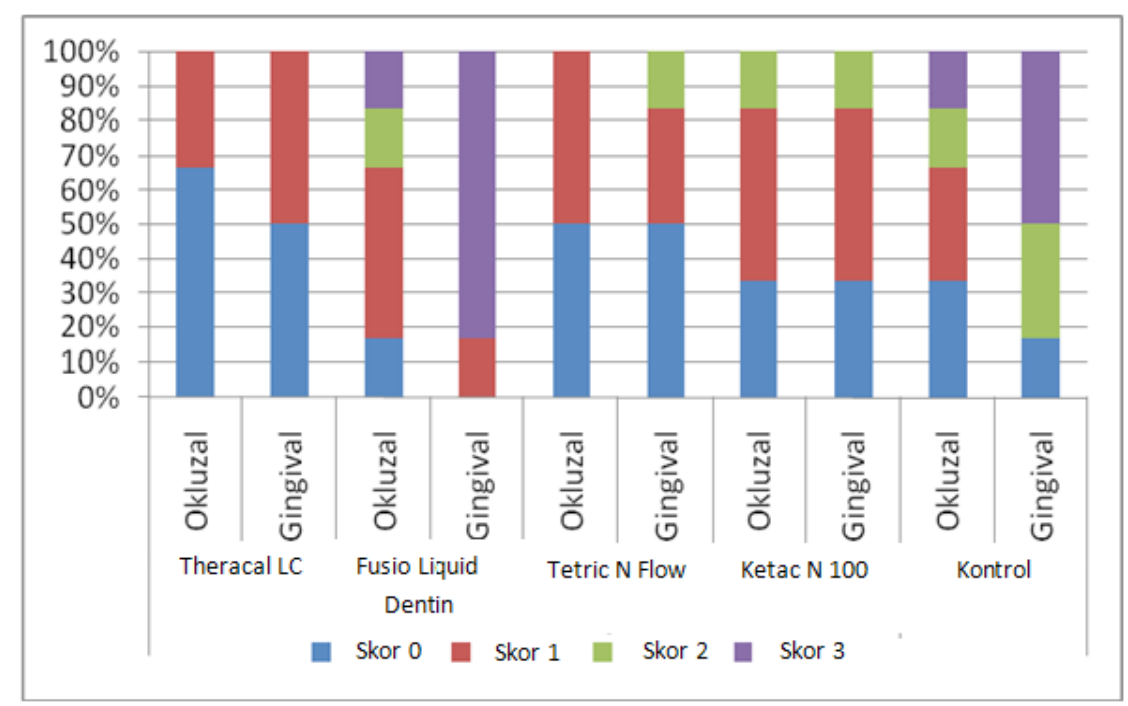

Şekil 1. Grupların sızıntı skorlarının yüzdesel dağııımı

Ayrıca, üretici firma ışıkla polimerizasyondan sonra, materyalin yüksek fiziksel özelliklere ve düşük erime özelliğine sahip olması nedeniyle üzerine daimi restoratif materyalin hemen yerleştirilmesine izin verdiğini de bildirmiştir. Diğer bir çalışmada da Cantekin ${ }^{20}$ TheraCal LC'nin metakrilat esaslı kompozitlere, silorane ve cam iyonomer esaslı restoratif materyallere göre daha iyi bağlanma gösterdiğini rapor etmiştir. Çalışmamızda hem okluzal hem de gingival bölgede en az mikrosızıntı rezin modifiye kalsiyum silikat materyal, TheraCal LC'nin kullanıldığı Grup 1'de görüldü. Grafik 1'deki mikrosızıntı skorları incelendiğinde, bu grupta sadece 'Skor 1' derecesinde mikrosızıntının görüldüğü saptandı. Bu da bu materyalin hem mine ve dentin hem de kompozite bağlanmasının iyi olduğunun bir göstergesi olabilir. Ancak bu materyalin diş dokuları yanısıra kompozite bağlanmasını inceleyen başka çalışmaların da yapılması gerekmektedir.

Çalışmada nanohibrit dolduruculu akışkan kompozit rezin, Tetric N-Flow'un kullanıldığı Grup 3'teki örneklerin hem okluzal hem de gingival bölgesinde görülen mikrosızıntı skorları istatistiksel olarak rezin modifiye kalsiyum silikat materyal, TheraCal LC'nin kullanıldığı Grup 1'e benzemesine rağmen, gingival bölgede mikrosızıntı görülen örneklerin bir kısmı 'Skor 1' diğer kısmı ise 'Skor 2' olarak değerlendirilmiştir. Bu da nanohibrit doldurucu içeren ve akışkan bir kompozit olan Tetric N-Flow'un dentin ile bağlanmasının TheraCal LC'ye göre daha zayıf olduğunun bir göstergesi olabilir. Alonso ve ark. ${ }^{21}$ akışkan kompozit rezinin kaide materyali olarak kullanıldığı sınıf $\mathrm{V}$ restorasyonlarda restorasyon kenarlarında mikrosızıntının daha az oluştuğunu bildirmişlerdir. Bu çalışmanın bulguları bizim çalışmamızın bulgularını desteklemektedir. Ancak Awliya ve El-Sahn ${ }^{22}$ akışkan kompozit kullanımının sınıf V kavitelerde mikrosızıntı oluşumunu engelleyemediğini rapor etmişlerdir. $\mathrm{Bu}$ çalışmanın bulguları da mikrosızıntının tamamen engellenemediğini gösteren bizim çalışmamızın bulgularını desteklemektedir.

Çalışmada nanodolduruculu rezin modifiye cam iyonomer siman, Ketac N100'ün kullanıldığı Grup 4'te okluzal ve gingival bölgelerde tespit edilen mikrosızıntı Grup 1 ve Grup 3'teki örneklerden fazla olmasına rağmen aralarında istatistiksel farklıı̆̆ın olmadığı saptandı. Rezin modifiye cam iyonomer simanların diş dokularına iyi bağlanma göstermeleri onların avantajları olarak gösterilmektedir. ${ }^{23}$ Ancak çalışmamızda bu grupta hem okluzal hem de gingival bölgede 2 örnekte 'Skor 2'nin görülmesi bu materyalin sınıf V kavitelerin yapısal özelliğinden dolayı diş dokularına yeterli bağlanma sağlayamadığı ve hatta bu materyal ile kompozit rezin arasındaki bağlanmanın da araştırılması gerektiğini ortaya çıkarmaktadır.

Çalışmada en fazla sızıntının kendinden bağlanabilen akışkan kompozit rezin, Fusio Liquid Dentin'in kullanıldığı Grup 2'de gözlendi. Bu grup ile hiç kaide materyali kullanılmayan kontrol grubu (Grup 5) örneklerinde gözlenen mikrosızıntı skorları arasında ise istatistiksel olarak anlamlı bir farklılığın olmadığı tespit edildi.

Fusio Liquid Dentin, kendinden pürüzlendirmeli, akışkan bir kompozit olup, hidrofilik bir yapıya sahiptir. Diş dokularına mikromekanik ve kimyasal olarak bağlanmaktadır. Bundan dolayı uygulanması esnasında dentin yüzeyine herhangi bir asitle pürüzlendirme ve bonding uygulaması yapılmamaktadır. Fusio Liquid Dentin'in yapısında 4-metkriloksi etiltrimetelitik asit (4-MET) bulunmaktadır. Bu fonksiyonel grup, hidroksi apatite ve dişe bağlanmayı sağlamaktadır. Ancak, nispeten zayıf bir monomer olmasından dolayı, dişe bağlanmasının zayıf olduğu rapor edilmiştir. ${ }^{24}$ Yapılan diğer çalışmalarda da kendinden bağlanabilen akışkan kompozit rezin, Fusio Liquid Dentin'in bağlanma 
dayanımının geleneksel sistemlerden düşük olduğu bildirilmiştir. ${ }^{25,26}$ Çalışmada Fusio Liquid Dentin'in kullanıldığı Grup 2'deki örneklerin tümünde mikrosızıntı olduğu tespit edildi. Diğer bir deyişle, bu grupta hiçbir örneğe 'Skor 0' (mikrosızıntının hiç olmadığı) değeri verilmediği gözlendi. Elde edilen bu bulgumuzun, Fusio Liquid Dentin'in diş dokularına bağlanmasının zayıf olması neden olabilir.

Kaide uygulanmayan kontrol grubunda gözlenen mikrosızıntının istatiksel olarak anlamlı olmazsa da Grup 2'den az olmasının nedeni, kulladığımız adeziv ve uyguladığımız kavitede bağlanma yüzeylerinin mineden ziyade dentin ve sementte olmasından ileri gelebilir. Nitekim, literatürde kullandığımız tek aşamalı kendinden pürüzlendirmeli bir adeziv olan Clearfil S3 Bond'un dentine bağlanmasının iyi olduğunu gösteren çalışmalar da bulunmaktadır. ${ }^{27}$

Bu çalışmada elde ettiğimiz diğer bir bulgu da tüm deney grupları kendi içlerinde değerlendirildiğinde, kavitenin okluzal ve gingival bölgelerindeki mikrosızıntı skorları arasında anlamlı farklılığın olmamasıdır. Bunun nedeninin sınıf $\mathrm{V}$ kavitelerin hazırlanma şekliyle ilişkili olduğunu düşünmekteyiz. Şöyle ki, çalışmada açtığımız kavitelerin servikal sınırı mine-dentin bileşiminin $1 \mathrm{~mm}$ altında sonlanacak şekilde oluşturuldu. Minenin kalınlığı ve mine prizmalarının yönü dişin okluzal veya insizal kenarıyla mine-sement bileşimi bölgesinde farklılık gösterir. Mine-sement bileşimde mine daha incedir ve asıl bağlanma dentin ve sement ile gerçekleşir. Bu nedenle çalışmamızda kaide materyali kullandığımız halde okluzal bölgede mikrosızıntı oluşumunun engellenemediği hatta gingival bölgede görülen mikrosızıntıya yakın skorlar elde edildiği kanısındayız.

Çalışmada elde edilen tüm bulgular doğrultusunda; sınıf V kompozit rezin restorasyonlarda kaide materyali olarak rezin modifiye kalsiyum silikat siman, akışkan kompozit ve rezin modifiye camiyonomer simanın kaide olarak kullanımının mikrosızıntı oluşumun önleyemediği, ancak kaide materyali kullanılmayan kontrol grubu ile kıyaslandığında mikrosızıntının daha az oranda görüldüğü tespit edildi. Çalışmada kullanılan kendinden bağlanabilen akışkan kompozit rezinin (Fusio Liquid Dentin) kompozit restorasyonun sızdırmazıı̆ına anlamlı bir katkısının olmadığı tespit edildi. Bu durumda başlangıç hipotezi kısmen reddedilmiş oldu. Mikrosızıntının sıklıkla görüldüğü sınıf V restorasyonlarda kaide materyali kullanımı tavsiye edilebilir. Ancak kullanılacak kaide materyalinin seçiminde dikkatli olunmalıdır.

\section{Sonuç}

$\mathrm{Bu}$ çalışmanın sınırları dahilinde, sınıf $\mathrm{V}$ restorasyonlarda kaide materyali kullanımının (Fusio Liquid Dentin hariç) gingival bölgedeki mikrosızıntıyı azalttığı ortaya konmuştur.

\section{TEŞEKKÜR VE ANMA}

Bu makale 27-30 Eylül 2012 tarihinde Girne'de (KKTC) düzenlenen 17. Diş Hastalıkları ve Tedavisi Anabilim Dalları Toplantısı'nda poster olarak sunulmuştur.

Çıkar çatışması: Yazarlar bu çalışmayla ilgili herhangi bir çıkar çatışmalarının bulunmadığını bildirmişlerdir.

\section{KAYNAKLAR}

1. Demirci M, Özer F, Kuşdemir M, Şar Sancaklı H, Karakaya Ş. Adeziv sistemlerin farklı uygulama şekillerinin V. Sınıf kavitelerdeki mikrosızıntı üzerine etkileri. Selcuk Dent J 2007;16:29-38.

2. Nguyen C. A new in vitro method for the study of micro-leakage of dental restorative materials [tez]. Adelaide: The University of Adelaide; 2007.

3. Larson TD. The clinical significance of marginal fit. Northwest Dent 2012;91:22-9.

4. Oliveira LC, Duarte S, Araujo CA, Abrahão A. Effect of low-elastic modulus liner and base as stress-absorbing layer in composite resin restorations. Dent Mater 2010;26:159-69.

5. Hilton TJ. Keys to clinical success with pulp capping: a review of the literature. Oper Dent 2009;34:615-25.

6. Gupta, PK, Garg G, Kalita C, Saikia A, Srinivasa TS, Satish G. Evaluation of sealing ability of biodentine as retrograde filling material by using two different manipulation methods: An in vitro study. J Int Oral Health 2015;77:111-4.

7. Larson TD. The clinical significance and management of microleakage. Part two. Northwest Dent 2005;84:15-9.

8. Kidd EA. Microleakage: a review. J Dent 1976;4:199-206.

9. Erdemir U, Yaman BC. Diş hekimliğinde mikrosızıntı ve mikrosızıntı araşıırma yöntemleri. J Istanbul Univ Fac Dent 2011;45:25-35.

10. Kaplan I, Mincer HH, Harris EF, Cloyd JS. Microleakage of composite resin and glass ionomer cement restorations in retentive and nonretentive cervical cavity preparations. J Prosthet Dent 1992;68:61623.

11. Sidhu SK. Sealing effectiveness of light-cured glass ionomer cement liner. J Prosthet Dent 1992;68:891-4.

12. Senawongse $P$, Pongprueksa $P$, Tagami J. The effect of the elastic modulus of low-viscosity resins on the microleakage of Class $\mathrm{V}$ resin composite restorations under occlusal loading. Dent Mater $\mathrm{J}$ 2010;29:324-9.

13. Vichi A, Margvelashvili M, Goracci C, Papacchini F, Ferrari M. Bonding and sealing ability of a new self-adhering flowable composite resin in class I restorations. Clin Oral Investig 2013;17:1497-506.

14. Mahrous Al, Eltiti HA, Ahmed IM, Alagha El. Effect of different gingival margin restorations of class II cavities on microleakage: an invitro study. Electron Physician 2015;77:1435-40.

15. Celik EU, Kucukyilmaz E, Savas S. Effect of different surface pretreatment methods on the microleakage of two different self-adhesive composites in Class V cavities. Eur J Paediatr Dent 2015;16:33-8.

16. He Z, Shimada Y, Sadr A, Ikeda M, Tagami J. The effects of cavity size and filling method on the bonding to Class I cavities. J Adhes Dent 2008;10:447-53.

17. Sampaio PC, Almeida Júnior AA, Francisconi LF, Casas-Apayco LC, Pereira JC, Wang L. Effect of conventional and resin-modified glass-ionomer liner on dentin adhesive interface of Class I cavity walls after thermocycling. Oper Dent 2011;36:403-13.

18. Estrela C, Holland R. Calsium hydroxide: study based on scientific evidences. J Appl Oral Sci 2003;11:269-82.

19. Gandolfi MG, Siboni F, Prati C. Chemical-physical properties of TheraCal, a novel light-curable MTA-like material for pulp capping. Int Endod J 2012;45:571-9.

20. Cantekin K. Bond strength of different restorative materials to light-curable mineral trioxide aggregate. J Clin Pediatr Dent 2015;39:143-8. 
21. Alonso RC, Sinhoreti MA, Correr Sobrinho L, Consani S, Goes MF. Effect of resin liners on the microleakage of Class $V$ dental composite restorations. J Appl Oral Sci 2004;12:56-61.

22. Awliya WY, El-Sahn AM. Leakage pathway of Class $V$ cavities restored with different flowable resin composite restorations. Oper Dent 2008;33:31-6

23. Lin A, Mclntyre N, Davidson R. Studies on the adhesion of glass ionomer cements to dentin. J Dent Res 1992;71:1831-41.

24. Poitevin A, De Munck J, Van Ende A, Suyama Y, Mine A, Peumans $\mathrm{M}$, et al. Bonding effectiveness of self-adhesive composites to dentin and enamel. Dent Mater 2013;29:221-30.

25. Vichi A, Margvelashvili M, Goracci C, Papacchini F, Ferrari M. Bonding and sealing ability of a new self-adhering flowable composite resin in class I restorations. Clin Oral Investig 2013;17:1497-506.

26. Fu J, Kakuda S, Pan F, Hoshika S, Ting S, Fukuoka A, et al. Bonding performance of a newly developed step-less all-in-one system on dentin. Dent Mater J 2013;32:203-11.

27. El-Damanhoury HM, Gaintantzopoulou M. Effect of thermocycling, degree of conversion, and cavity configuration on the bonding effectiveness of all-in-one adhesives. Oper Dent 2015;40:480-91.

\section{Effect of using different base materials on microleakage of class $\mathrm{V}$ restorations}

\section{Abstract}

OвJеCтIVE: The aim of this in vitro study was to evaluate and compare the effect of using different base materials on microleakage of class $\mathrm{V}$ restorations.

Materials and Method: In this study 60 extracted noncavitated human molar teeth were used. Class V cavities were prepared on the buccal surfaces in $4 \mathrm{~mm}$ mesio- distal, $3 \mathrm{~mm}$ gingivo-occlusal width and $3 \mathrm{~mm}$ depth. The teeth were randomly divided into five groups: Group 1: resin-modified calcium silicate material (TheraCal LC), Group 2: self-adhesive flowable composite resin (Fusio Liquid Dentin), Group 3: flowable composite resin liner (Tetric N Flow), Group 4: resin-modified glass ionomer liner (Ketac N100), Group 5: control group. Materials in the experimental groups were placed in $1 \mathrm{~mm}$ thickness as liner. Then, a nanohybrid composite resin (Grandio) was placed and restorations were completed. In the control group, no base material was applied. After finishing and polishing procedures, thermocycling was performed 5000 times between $5-55^{\circ} \mathrm{C}$. Microleakage of restorations was evaluated by using dye penetration method (basic fuchsin). Results were analyzed by Kruskal Wallis with Bonferroni correction and Mann-Whitney $U$ tests.

RESULTS: Regarding occlusal microleakage, no statistically significant difference was found between the groups $(p=0.267)$; however significant difference was found between the gingival microleakage scores $(p=0.004)$. Compared to Fusio Liquid Dentin and control groups, significantly less dye penetration was found in Theracal LC, Tetric N-Flow and Ketac $\mathrm{N}-100$ groups $(\mathrm{p}<0.01)$. No significant difference was found between the occlusal and gingival sides of the restorations in any of the test group $(p>0.01)$.

Conclusion: Within the limitation of this study, the conclusion was that the use of a liner (except Fusio Liquid Dentin) under composite resin in a class $\mathrm{V}$ cavity reduced the microleakage of the restoration.

KEYwORDS: Composite dental resin; dental cavity liners; dental leakage 